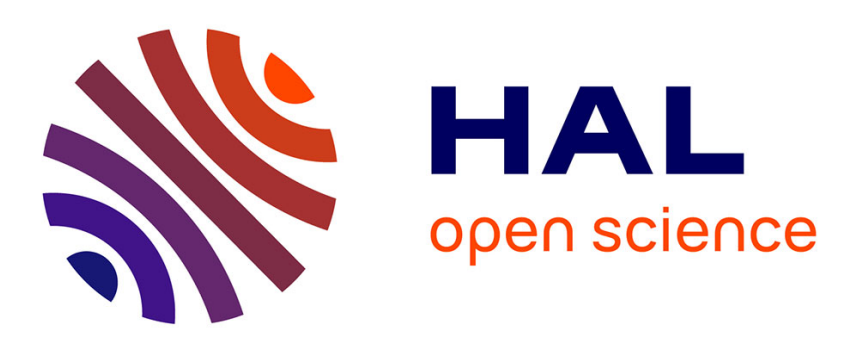

\title{
Strontium-doped organic-inorganic hybrids towards three-dimensional scaffolds for osteogenic cells
}

Łukasz John, Marta Podgórska, Jean-Marie Nedelec, Łucja Cwynar-Zając, Piotr Dzięgiel

\section{- To cite this version:}

Łukasz John, Marta Podgórska, Jean-Marie Nedelec, Łucja Cwynar-Zając, Piotr Dzięgiel. Strontiumdoped organic-inorganic hybrids towards three-dimensional scaffolds for osteogenic cells. Materials Sciences and Engineering: C, 2016, 68, pp.117-127. 10.1016/j.msec.2016.05.105 . hal-01336146

\author{
HAL Id: hal-01336146 \\ https://hal.science/hal-01336146
}

Submitted on 23 Jun 2016

HAL is a multi-disciplinary open access archive for the deposit and dissemination of scientific research documents, whether they are published or not. The documents may come from teaching and research institutions in France or abroad, or from public or private research centers.
L'archive ouverte pluridisciplinaire HAL, est destinée au dépôt et à la diffusion de documents scientifiques de niveau recherche, publiés ou non, émanant des établissements d'enseignement et de recherche français ou étrangers, des laboratoires publics ou privés.

\section{(c)(1)}

Distributed under a Creative Commons Attribution| 4.0 International License 


\title{
Strontium-doped organic-inorganic hybrids towards three- dimensional scaffolds for osteogenic cells
}

Łukasz John, ${ }^{\mathrm{a}, \star}$ Marta Podgórska, ${ }^{\mathrm{a}}$ Jean-Marie Nedelec, ${ }^{\mathrm{b}, \mathrm{c}}$ Łucja Cwynar-Zając, ${ }^{\mathrm{d}}$ and Piotr Dzięgiel ${ }^{d, e}$

${ }^{a}$ Faculty of Chemistry, University of Wrocław, 14 F. Joliot-Curie, 50-383 Wrocław, Poland

${ }^{b}$ Université Clermont Auvergne, SIGMA Clermont, Institut de Chimie de Clermont-Ferrand, BP 10448, F63000 Clermont-Ferrand, France

${ }^{c}$ CNRS, UMR 6296, ICCF, F-63178 Aubiere, France

${ }^{d}$ Department of Histology and Embryology, Wrocław Medical University, 6a Chałubińskiego, 50-368 Wrocław, Poland

${ }^{e}$ Department of Physiotherapy and Occupational Therapy in Conservative and Interventional Medicine, 35 Paderewskiego, 51-612 Wrocław, Poland

KEYWORDS: Bone, organic-inorganic hybrids, osteoblasts, scaffolds, osteoporosis, strontium

Corresponding author: Dr. Łukasz John, e-mail: lukasz.john@chem.uni.wroc.pl

\begin{abstract}
Biomimetic organic-inorganic hybrid bioscaffolds are developed to complement or replace damaged fragments in bone tissue surgery. The aim of this work was to develop a simple and fast method to prepare composite material for bone engineering, avoiding time consuming and complex methodologies. The resulting materials (also called in this work as hybrid composites or hybrid scaffolds) have a three-dimensional
\end{abstract}


macroporouspolymer-like network derived fromtriethoxyvinylsilane (TEVS) and 2hydroxyethylmethacrylate (HEMA) monomers, with incorporated calcium, strontium, and phosphate ions. The materials were fully characterized using FT-IR,biomineralization studies, scanning electron microscopy (SEM), energy dispersive X-ray spectroscopy, scratch tests, Young's modulus and compressive strength tests, and gas physisorption. We report a comprehensive study on the in vitro effect of novel strontium doped materials on human bone cells. In vitro investigations were conducted using a normal human osteoblast cell line that mimics the cellular events of the in vivo intramembranous bone formation process. The materials do not have a negative impact on the survival of the normal human osteoblasts; moreover, materials doped with strontium show that not only are cells able to survive, but they also attach to and grow on a bioscaffolds surface. For this reason, they may be used in future in vivo experiments. 


\section{Introduction}

Biomimetic materials with structures that have hierarchical interconnected pores and a network-like nature, have been intensively studied in recent years, because they form excellent scaffolds for biomedical applications, including controlled drug release, sophisticated substitutes for tissue engineering, bioresorbable structures, etc. Such scaffolds are used as tissue templates because they can simultaneously form an ideal structure that is necessary to ensure cell growth and viability [1]. Inside the body, such materials induce a complex series of physicochemical reactions that lead to the formation of an interfacial bone-like apatite layer $[2,3]$. The dissolution of biomaterial devoted to bone replacement induces ion exchanges with biological fluids (or their mimics) enabling the formation of a mineral phase(s), direct interfacial binding between bioactive material and the bone; it should be emphasized that a number of review papers described this issue $[1,2]$. Here, both textural properties and chemical composition must be chosen in such a way that the material might be used as an efficient implant, creating a strong interfacial bond with host tissues, and which is extremely important, stimulating bone cell adhesiveness, differentiation, and proliferation [4].

Strontium has been used as a medicinal additive for more than a hundred years and its use as a dietary supplement is reported as the way to maintain strong bones [5-7]. Since the development of strontium ranelate, which is a drug that reduces the incidence of fractures in patients with osteoporosis, there has been an increasing awareness of the biological role of strontium - especially its role in bone and in interactions with calcium ions [8].Furthermore, in the literature there are several examples of various 
biomaterials, including scaffolds, containing $\mathrm{Sr}^{2+}$ ions [9-11]. Among the trace metals present in human bone, strontium is mainly, but not solely, correlated with bone compression strength [12]. As an alkaline earth that is closely chemically related to calcium, strontium affects bone formation and resorption through direct and indirect effects on bone cells or bone minerals. It also has an anabolic activity that is very important from a bone balance point of view, as can be seen by comparing healthy and osteopenic skeletons [5, 13].

There has been a greater interest in the biological role of strontium has arisen since the discovery of its beneficial effect on bone, involving the reduction of incidence of fractures in osteoporotic patients $[14,15]$. Osteoporosis is a disease that causes thinning of the bones with a reduction in bone mass due to depletion of calcium and bone protein. Hence, the amount of bone tissue in a certain volume of bone dramatically decreases. It has been shown that strontium, as a bone-seeking agent, inhibits bone resorption, decreases osteoclast activity, and inhibits bone-resorbing activity. In addition, strontium salts can increase bone mass without causing detectable bone mineralization defects [16-20]. The mechanism of the strontium action at the bone surface is not fully known, but some mechanisms are postulated. For instance, calcium receptors in some types of cell can be activated via the presence of $\mathrm{Sr}^{2+}$ cations, resulting in the activation of secondary messenger molecules used in signal transduction in biological cells [16].

In this study, we investigated the in vitro effect of strontium-doped organic-inorganic scaffolds manufactured using the sol-gel process on biological responses associated with osteoblast viability. In this manner, we examined human bone cell behavior on three-dimensional polymer-like networks based on HEMA and TEVS, with incorporated 
$\mathrm{Ca}^{2+}$ and $\mathrm{PO}_{4}{ }^{3-}$ ions and, additionally, doped with strontium. Selected samples were also covered with synthetic bone-like hydroxyapatite in order to compare their in vitro behavior to new systems reported in this paper. To prepare mentioned above materials we used well-known monomers, e.g. HEMA which is safe for human and is already used in medicine $[21,22]$. We report on a simple and fast method to obtain interconnected porous scaffolds for bone engineering with mechanical properties similar to those in human bones. In addition, a desirable feature of the obtained formulations based on creating a strong interfacial bond with host cells and tissues was studied on a normal human osteoblast cell line (NHOst), which mimics the cellular events of the in vivo intramembranous bone formation process. According to our best knowledge, such formulations possessing this sort of matrix with mentioned above dopants have not been studied so far, both taking into consideration their chemical and mechanical properties, and also in vitro studies.

\section{Materials and methods}

\subsection{Materials for synthesis}

TEVS, HEMA, triethylphosphate $\left(\left(\mathrm{C}_{2} \mathrm{H}_{5} \mathrm{O}\right)_{3} \mathrm{PO}\right.$, used as a source of $\mathrm{PO}_{4}{ }^{3-}$ anions), and tert-butyl hydroperoxide ( 5.5 $\mathrm{M}$ in decane) were purchased from Aldrich, Germany, and used without further purification. Calcium dichloride dihydrate $\left(\mathrm{CaCl}_{2} \cdot 2 \mathrm{H}_{2} \mathrm{O}\right.$, used as a source of $\mathrm{Ca}^{2+}$ cations), and strontium dichloride hexahydrate $\left(\mathrm{SrCl}_{2} \cdot 6 \mathrm{H}_{2} \mathrm{O}\right.$, a source of $\mathrm{Sr}^{2+}$ cations) were purchased from Sigma-Aldrich, Germany. An aqueous solution of $0.01 \mathrm{M}$ hydrochloric acid was prepared from $37 \% \mathrm{HCl}$ (Chempur, Poland). Acetic acid 
(80\%), $25 \%$ aqueous ammonia solution, ammonium carbonate $\left(\left(\mathrm{NH}_{4}\right)_{2} \mathrm{CO}_{3}\right)$, and sodium dihydrogen phosphate dihydrate $\left(\mathrm{NaH}_{2} \mathrm{PO}_{4} \cdot 2 \mathrm{H}_{2} \mathrm{O}\right)$ were purchased from $\mathrm{POCh}$, Poland.

\subsection{Material characterization}

Microanalyses were conducted using an elemental analyzer 2400 CHNS Vario EL III (Elementar). The concentration of metal ions was determined by the inductively coupled plasma technique, using an ARL model 3410 sequential spectrometer (Fisons Instruments). Infrared spectra were recorded on a Bruker 66/s FT-IR spectrophotometer in $\mathrm{KBr}$ pellets. All materials were characterized by recording $\mathrm{X}$-ray powder diffraction patterns using a Bruker D8 ADVANCE diffractometer equipped with a copper lamp ( $\lambda_{\text {Cuka }}$ $=1.5418 \AA$ ). Standard measurements were performed for $2 \theta=10-90^{\circ}$, in increments of $0.016^{\circ}$ with a counting time of $0.3 \mathrm{~s}$. Scaffold morphology was tested by high-resolution transmission electron microscopy, using an FEI Tecnai G2 20 X-TWIN microscope operating at $200 \mathrm{kV}$ and providing $0.25 \mathrm{~nm}$ resolution, and equipped with an energy dispersive X-ray spectroscopy microanalyzer, and SEM, using a Hitachi S-3400N microscope equipped with an EDS ThermoNoran System SIX. pH values were measured using an ELMETRON pH meter CP-401. Viscosity of prepared sols was measured using RVDV-I Prime rotary viscometer (Brookfield Engineering Laboratories) equipped with RV spindle set. Scratch tests were performed using a Wolff-Wilborn pencil hardness tester. The density of the resulting materials was measured using a gas pycnometer on an Ultrapyc 1200 e (Quantachrome Instruments). Mechanical properties, including Young's modulus and compressive strength, were studied using a TA-XT texture analyzer (TA Plus, Lloyd Instruments) equipped with mechanical grips and 
ElectroForce 5100 BioDynamic Test Instrument from BOSE company. Nitrogen porosimetry was performed at $77 \mathrm{~K}$ on a Micromeritics ASAP 2020M system. The specific surface area $\left(\mathrm{S}_{\mathrm{BET}}\right)$ was calculated by the Brunauer-Emmett-Teller method. The mesopore size distribution was determined using the Barrett-Joyner-Halenda method, applied on the desorption branch.

\subsection{Preparation of the organic-inorganic hybrid materials}

Organic-inorganic hybrid materials, labeled 1HCP, 1HCP_H, 1HCPP, 1HCPS, 1HCPS_H, and 1HCPSP, were prepared using the sol-gel process. There are two types of sample. The first is composed of TEVS and HEMA, and is doped with $\mathrm{Ca}^{2+}$ and $\mathrm{PO}_{4}{ }^{3-}$ ions (1 HCP-type materials). The second group of materials is additionally enhanced with strontium cations (1HCPS-type materials). Some samples in each group were biomineralized in biomimetic fluids (1HCPP and 1HCPSP) or covered with synthetic bone-like hydroxyapatite (1HCP_H and 1HCPS_H). For detailed labels, compositions, and comments, see Table 1.

In a typical synthesis, the mixture of TEVS/HEMA was dissolved in anhydrous ethanol mixed with an aqueous solution of $0.01 \mathrm{M} \mathrm{HCl}$. Hydrochloric acid was used as a catalyst for the hydrolysis and condensation reactions. The mixture was polymerized by heat treatment at $70{ }^{\circ} \mathrm{C}$ in the presence of tert-butyl hydroperoxide, which is commonly used as an initiator in radical polymerization. Next, the obtained solution was vigorously stirred for $5 \mathrm{~h}$ and then cooled to room temperature. To obtain doped materials, the resulting composite solution was mixed with $\mathrm{CaCl}_{2} \cdot 2 \mathrm{H}_{2} \mathrm{O}, \mathrm{SrCl}_{2} \cdot 6 \mathrm{H}_{2} \mathrm{O}$ and $\left(\mathrm{C}_{2} \mathrm{H}_{5} \mathrm{O}\right)_{3} \mathrm{PO}$, 
leaving an hour interval between each addition, and the resulting mixture was left overnight, with stirring.

\subsection{Preparation of porous scaffolds}

Appropriate sugar templates were prepared from commercially available granulated sugar mixed with ammonium carbonate (3-5 wt\%), moistened with evaporated copolymer solution, and closely packed in cubic plastic molds $(4 \times 4 \mathrm{~cm})$. The sugar was left in the molds at $65^{\circ} \mathrm{C}$ until the gelation process occurred. The sugar template was then washed out using warm distilled water $\left(40-50^{\circ} \mathrm{C}\right)$ until the filtrate had no traces of sugar. The presence of sugar was examined using the Molisch ( $\alpha$-naphthol) test. The chemical basis of this reaction is the production of furfural derivatives on heating carbohydrates with naphthols to give colored compounds. A reddish violet appears in the presence of a very small amounts of carbohydrates. The complete elimination of ammonia produced during decomposition of carbonate salt was examined using elemental analysis.

\subsection{The Molisch test}

In a standard procedure, $0.5 \mathrm{~mL}$ of the filtrate was mixed with $5 \mathrm{~mL}$ of cold $75 \% \mathrm{H}_{2} \mathrm{SO}_{4}$. Three drops of a $3 \%$ a-naphthol solution in ethanol were added to the acid mixture. A yellow color is produced by the addition of the naphthol. After this, the mixture was warmed up on a water bath at $80^{\circ} \mathrm{C}$. Depending on the amount of carbohydrates, a red to blue-violet color appears throughout the whole mixture. In the absence of carbohydrates, the examined solution remains yellow. 


\subsection{Biomineralization assay}

The biomineralization process was performed by soaking the hybrid samples in Dulbecco's modified Eagle's medium (DMEM), maintaining the solution at $37^{\circ} \mathrm{C}$. The process was conducted using a static protocol; this means that the DMEM was introduced once, without exchanging the biological fluid in the container. Samples after exposition in DMEM were washed out using distilled water (three washes with $5 \mathrm{~mL}$ ), to remove any water-soluble inorganic salts, and then using acetone (three washes with 5 $\mathrm{mL}$ ) and dried under compressed air. The newly formed inorganic layer was characterized using FT-IR spectroscopy, X-ray powder diffraction, energy dispersive Xray spectroscopy, and elemental analysis. The infrared spectra and elemental analyses were measured on approximately $1 \mathrm{mg}$ of material directly scraped from the samples' surfaces. The X-ray powder diffraction and energy dispersive X-ray spectroscopy measurements were carried out on the surfaces of the samples. The ion concentration in the biological medium was measured for different soaking times $(0.5,1,6$, and $12 \mathrm{~h}$, and $1,2,3,4$, and 7 days), using inductively coupled plasma analysis. Additionally, X-ray powder diffraction for all samples was performed after 7-9 weeks of soaking in DMEM solution, to confirm the nature of the mineral phase that crystallized or precipitated on the materials' surfaces.

\subsection{Preparation of samples covered in synthetic hydroxyapatite}

First, $16.17 \mathrm{~g}(109.99 \mathrm{mmol})$ of $\mathrm{CaCl}_{2} \cdot 2 \mathrm{H}_{2} \mathrm{O}$ and $10.30 \mathrm{~g}(66.02 \mathrm{mmol})$ of $\mathrm{NaH}_{2} \mathrm{PO}_{4} \cdot 2 \mathrm{H}_{2} \mathrm{O}$ were added to $100 \mathrm{~mL}$ of distilled water and dissolved by stirring at room temperature. Next, the resulting clear solution was poured into a measuring flask 
and $35.08 \mathrm{~mL}$ of $80 \%$ acetic acid was added and the volume made up to $1 \mathrm{~L}$ with distilled water. The hybrid scaffolds were evaporated under vacuum to remove the air from the pores. Then, the evaporated samples were placed in a beaker (volume, $35 \mathrm{~mL}$, height, $50 \mathrm{~mm}$ ), and flooded with the prepared solution. To a second beaker (the same size), $4 \mathrm{~mL}$ of $25 \% \mathrm{NH}_{3(\mathrm{aq})}$ was added. Both beakers were covered with punched Parafilm, to reduce the diffusion of ammonia, and placed in a sealed chamber (volume, $1 \mathrm{~L})$. After $48 \mathrm{~h}$, the scaffolds were removed from the solution, washed out using distilled water (three washes of $15 \mathrm{~mL}$ ) and dried under vacuum at $60^{\circ} \mathrm{C}$. The composition of the synthetic hydroxyapatite was confirmed using FT-IR spectroscopy and X-ray powder diffraction.

\subsection{Young's modulus and compressive strength}

The Young's modulus and compressive strength were determined for monoliths and scaffolds for both $1 \mathrm{HCP}$ and 1HCPS systems. These preliminary studies were carried out to determine the materials' utility as potential implants in bone tissue engineering. The collected data were compared with results obtained for cortical [23-26] and cancellous bone [27-30] in the case of monoliths and scaffolds, respectively. The mechanical tests were performed with ElectroForce 5100 BioDynamic Test Instrument from BOSE company and using a TA-XT texture analyzer (TA Plus, Lloyd Instruments) equipped with mechanical grips. Test instruments provide accurate characterization of biomaterials and biological specimens. They can be used for the evaluation of a variety of specimens, including biomaterials, cellular and cell-seeded scaffolds, native tissue 
samples and tissue-engineered constructs. The obtained data were average value of measured factor \pm standard deviation. All samples were measured at least 7 times.

2.9. Contact angle and surface free energy measurements using the Owens-Wendt method

The surface free energy $(\gamma)$ and its dispersive $\left(\gamma^{d}\right)$ and polar $\left(\gamma^{p}\right)$ components were determined for the obtained materials using contact angle measurements and the Owens-Wendt method [31, 32]. The aqueous contact angle analysis was carried out using sessile drop method and a DataPhysics OCA20 instrument to determine the wettability of the resulting coatings. The averages of at least five readings taken at different locations on each sample surface were calculated.

\subsection{Scratch tests}

Scratch tests were performed on a glass surface covered by a thin film of resulting materials. A pencil hardness test was carried out according to Chinese standard GB/T6739-2006.

\subsection{Human osteoblast cell culture}

Cells from NHOst were cultured in osteoblast growth basal medium supplemented with $10 \%$ fetal bovine serum, $0.1 \%$ ascorbic acid, and $0.1 \%$ gentamycin. The cell line and supplements were obtained from Lonza, Belgium. The adherent cells were cultured in 75 $\mathrm{cm}^{2}$ flasks (Becton Dickinson, USA). The cells were maintained at $37{ }^{\circ} \mathrm{C}$ in a fully 
humidified atmosphere at $5 \% \mathrm{CO}_{2}$ in air (Hera Cell Heraeus, Germany). The cell line populations used in this experiments were taken between passages 5 and 6 .

\subsection{Cytotoxicity evaluation of hybrid biocomposites on the NHOst cell line}

In this studies both monoliths and foam-like samples were considered. Cylindrical specimens from each type of material with a 'diameter $x$ height' dimensions: $6 \mathrm{~mm} \times 2$ $\mathrm{mm}$ and $12 \mathrm{~mm} \times 10 \mathrm{~mm}$ for monoliths and scaffolds, respectively were investigated. In the SRB assay 1 sample (monolith or scaffold) per well of plate was added.Cells in the exponential growth phase were seeded at $0.2 \times 10^{6}$ cells/well on 24-well plates (Becton Dickinson, USA), and then incubated for $24 \mathrm{~h}$. On the second day, after fixing the cells, the culture medium was refreshed and the following biocomposite samples were placed on the cells: 1HCP, 1HCP_H, 1HCPP, 1HCPS, 1HCPS_H, and 1HCPSP. The plates were incubated for $72 \mathrm{~h}$. After this time, a sulforhodamine B assay (SRB assay) (Sigma, USA) was performed [33], to measure cell survival, after prior fixation of cells with trichloroacetic acid (Sigma, USA) [34]. Absorbance at a wavelength of $562 \mathrm{~nm}$ was measured on a plate reader (Tecan Infinite M200 Pro, Austria). Three independent repetitions of each test were performed.

\subsection{Preparation of NHOst cell line for SEM}

Prior to seeding the cells on the hybrid biocomposites, samples of $1 \mathrm{HCPS}$ were incubated for $24 \mathrm{~h}$ in osteoblast growth basal medium (Lonza, Belgium). The next day,

cells at the exponential growth phase were seeded at $10^{5}$ cells per sample and placed in a 12-well plate (Becton Dickinson, USA). This seeding procedure was repeated twice 
more, on days 9 and 16 of incubation. Throughout the whole experiment, the medium was changed every 2-3 days. After 20 days, the cells were fixed for SEM. The samples were washed with phosphate buffered saline to remove unfixed cells, and the scaffolds were fixed in $2.5 \%$ glutaraldehyde (Serva, Germany) prepared on a $0.2 \mathrm{M}$ cacodyl buffer (Serva, Germany) for $1 \mathrm{~h}$ at $4^{\circ} \mathrm{C}$. The samples were then rinsed three times in cacodyl buffer for 5 min, refixed with $1 \%$ osmium tetroxide (Serva, Germany) for $1 \mathrm{~h}$ at $4{ }^{\circ} \mathrm{C}$, and finally rinsed three times with $0.2 \mathrm{M}$ cacodyl buffer for 5 minutes. The samples were then dehydrated through a series of graded alcohol solutions (Chempur, Poland) with incubation for 15 minutes in each solution (50, 70, 80, and 96\%). After three 15-minute incubation periods in absolute alcohol (Chempur, Poland), the samples were transferred to acetone (Chempur, Poland).

\subsection{Statistical analysis}

All results were obtained by performing three independent replicates of each experiment. The results are expressed as means \pm standard deviations. Statistical analysis was carried out using Dunnett's multiple comparison test. Values of $P<0.05$ were considered statistically significant.

\section{Results and discussion}

\subsection{Synthesis of organic-inorganic hybrid materials}

Organic-inorganic hybrid materials were synthesized using the sol-gel process. The polymer network constitutes a mixture of TEVS and HEMA in a 1:4 molar ratio. The presence of specific groups of the synthesized composites were determined from FT-IR 
spectroscopy. In the spectra, the characteristic absorption bands of siloxane Si-O-Si moiety are observed at $\sim 1040,800$ and $470 \mathrm{~cm}^{-1}$. The peaks at $\sim 1490,1415$ and 870 $\mathrm{cm}^{-1}$ are assigned to the $\mathrm{C}-\mathrm{O}$ vibration bands. It should be noted that for samples containing phosphate ions their bands are not present in the spectra, because they are overlapped by various organic groups. In turn, peak at $\sim 3420 \mathrm{~cm}^{-1}$ is matched to hydroxyl group. Such substrates were chosen for this specific purpose. Not only are the compounds able to form linear chain copolymers and cross-linking connections spontaneously, but they also create a specific polymer network that strongly affects the scaffold's strength. In TEVS, (i) EtO- ions allow hydrolysis to form silanol groups, (ii) silanols allow condensation/polycondensation to form siloxane moieties, and additionally promote ions' exchange and hence bone-like apatite formation, and (iv) vinyl groups (also present in HEMA) allow polymerization [35]. In turn, HEMA is (i) biocompatible and already used in medicine; has wide applications such as contact or intraocular lenses, soft tissue replacement and vascular prostheses, and (ii) increases the immobilization of cells, bioactive molecules (e.g. enzymes) or pharmacological compounds [36]. The formation of various covalent bonds between organic chain fragments is possible because of reactive functional groups, such as vinyl $\left(-\mathrm{CH}=\mathrm{CH}_{2}\right)$ and hydroxyl $(-\mathrm{OH})$, which are present in the ramified matrix. In the TEVS/HEMA composite structure, the condensed silanol (三Si-OH) groups easily form siloxane (-Si-O-Si-) moieties that have an influence on the formation of strong connections between polymer chains (Fig. 1).

Moreover, silanols are able to promote the exchange of ions between the composite and the outer environment. As a consequence, the formation of various inorganic salts, such as phosphates and carbonates, is possible [35]. It is worth noting that the 
crystallization of such salts initiates bone growth and enables the treated bone fragment to recover. This also has a positive impact on cellular behavior and activity [37].

During syntheses, inorganic salts such as calcium and strontium chlorides and triethylphosphate were added. These salts constitute a source of calcium $\mathrm{Ca}^{2+}$, strontium $\mathrm{Sr}^{2+}$, and phosphate $\mathrm{PO}_{4}{ }^{3-}$ ions, respectively. As emphasized in Introduction paragraph, calcium and phosphorous salts are the key factors for bone tissue formation, while strontium salts can effectively decrease bone resorption and simultaneously increase bone formation, raising the possibility for potential usage in osteoporosis treatment strategies. It is worth noting that these materials possess a sufficient shelf life (in the liquid state before curing), of about 6 months. During this time viscosity equaled ca. $950 \mathrm{cP}$ and after 6 months viscosity rapidly grew up and sol transformed to transparent gel; this is important data for easy and wide distribution. Moreover, the developed process is simple, and does not require excessive costs or complex equipment. Homogeneous and transparent gels were obtained for all materials synthesized (Fig. 2).

\subsection{Structure of hybrid scaffolds}

Cancellous bone is a highly porous structure with a wide distribution of pore sizes and wall thicknesses [27-30]. The specific three-dimensional scaffold with a highly interconnected macroporous network and tunable mechanical properties is highly desirable in various medical applications [38]. The porosity and pore size of bioscaffolds play a crucial role in bone formation [39]. For pore sizes larger than $50 \mu \mathrm{m}$, tissue mineralization is observed; for bigger pores $(>100 \mu \mathrm{m})$ this process extends to a depth 
of $1000 \mu \mathrm{m}$ and there is a good chance that hard tissue can be firmly rebuilt. Moreover, the roughness of the scaffold's surface is indispensable for efficient cells' attachment, both in vitro and in vivo. It strongly affects cellular morphology, proliferation, and phenotype expression [40].

In this study, the resulting organic-inorganic hybrid materials constitute a perfect platform in the formation of biomimicking scaffolds for hard tissue engineering. Porous structures were created using sugar templates. This easily-leachable and biocompatible porogen enables the formation of macropores of $150-350 \mu \mathrm{m}$ in size that guarantee natural tissue ingrowth, mass transport, osteoinductive agent attachment, and ion exchange [41] (Fig. 3).

The total porous fraction for pure 1 HCPP and 1 HCPSP was approximately $90 \%$, corresponding to an apparent density of $\sim 0.25 \pm 0.01 \mathrm{~g} \mathrm{~cm}^{-3}$. In turn, the skeleton densities of the scaffolds were $2.488 \pm 0.009 \mathrm{~g} \mathrm{~cm}^{-3}$ and $2.479 \pm 0.008 \mathrm{~g} \mathrm{~cm}^{-3}$ for 1HCPP and 1HCPSP, respectively.

In addition to macroporosity, mesoporosity studies for both systems were also performed. Here, the Brunauer-Emmett-Teller surface area, average and modal pore diameters, and total pore volume were calculated. Surface areas were measured using the Brunauer-Emmett-Teller models for relative pressures of $0.05<\mathrm{p} / \mathrm{p}_{0}<0.30$. The surface areas were of the order of $21 \mathrm{~m}^{2} \cdot \mathrm{g}-1$ for both 1HCPP and 1HCPSP. By comparison with, e.g., macroporous bioactive glasses [42], these surface areas are smaller, probably arising from the deeper packing inside the network. Surface area also affects nanopore sizes. Analysis of nanopore size distribution was based on the Horvath-Kawazoe model. Nanopores were present in a wide range of sizes from 1.6 to 
$2.1 \mathrm{~nm}$ for both materials. It should be noted, as a general comment, that in vitro lower porosity effectively stimulates osteogenesis by suppressing cell proliferation and forcing cell aggregation. Conversely, such a trend results in diminished mechanical properties, thereby setting an upper functional limit for pore size and porosity [40].

The roughness of the scaffolds' surface was achieved via the addition of ammonia carbonate to sugar porogen. During decomposition of carbonate salt at about $60{ }^{\circ} \mathrm{C}$, gaseous carbon dioxide and ammonia are spontaneously liberated. Such vapor products play a dual role. While $\mathrm{CO}_{2}$ serves as an agent that additionally opens noninterconnected macropores, the released $\mathrm{NH}_{3}$ provides roughness of the surface. This is clearly shown in Fig. 4.

\subsection{Biomineralization}

The resulting organic-inorganic hybrids were soaked in biological medium (DMEM, the composition of which is almost equal to body fluids,) to provoke or induce crystallization of inorganic salts on their surfaces. The concentrations of calcium, silicon, phosphate and strontium ions in biological fluid were measured using inductively coupled plasma optical emission spectroscopy before ("pure" DMEM) and after (1HCPP and 1HCPSP) exposure after different time periods: $-0.5,1,6$, and12 h, and 1, 2, 3, 4, and 7 days. Initially, the concentrations of specific ions in DMEM were: $\mathrm{Ca}^{2+}, 67.97 \mathrm{mg} \mathrm{L}^{-1} ; \mathrm{Si}^{4+}, 0.11$ $\mathrm{mg} \mathrm{L}^{-1} ; \mathrm{PO}_{4}{ }^{3-}, 30.94 \mathrm{mg} \mathrm{L}^{-1} ; \mathrm{Sr}^{2+}, 0.00 \mathrm{mg} \mathrm{L}^{-1}$. In this study, biological medium was used because it additionally contains amino acids and vitamins and provides better biomimetic conditions. However, owing to the presence of various proteins in this 
solution, lower rates for the material's dissolution and a subsequent delay in surface layer formation are expected [43].

The dissolution experiments revealed that $\mathrm{Ca}^{2+}$ cations were released from the material in a different way for each of the 1HCPP and 1HCPSP systems (Fig. 5). In the 1HCPP system, the concentration of $\mathrm{Ca}^{2+}$ decreased in the first $15 \mathrm{~h}$. After this time, it returned to the initial value and remained constant for approximately $40 \mathrm{~h}$. Next, the quantity of $\mathrm{Ca}^{2+}$ dramatically decreased to $\sim 35-40 \mathrm{mg} \mathrm{L}^{-1}$ to achieve equilibrium. By contrast, in the 1HCPSP system, the concentration of calcium ions in the DMEM changed continuously in the first 3 days. The $1 \mathrm{HCPSP}$ system quickly released $\mathrm{Ca}^{2+}$ ions during the first $10 \mathrm{~h}$ of immersion, reaching $\sim 100 \mathrm{mg} \mathrm{L}^{-1}$ and then remained constant.

Similar changes were observed with the concentration of silicon ions. Firstly, for 1HCPP system, the concentration of silicon strongly varied and then reached $\sim 70-75$ $\mathrm{mg} \mathrm{L}^{-1}$ after $75 \mathrm{~h}$. The 1 HCPSP system released $\mathrm{Si}^{4+}$ ions more quickly; during the first $50 \mathrm{~h}$, a sharp increase in their concentration is observed. After this time, an equilibrium state of $\sim 25 \mathrm{mg} \mathrm{L}^{-1}$ was established.

The concentration of phosphate anions also fluctuated for the 1HCPP system. A state of equilibrium was achieved after $70 \mathrm{~h}$ and remained constant at $\sim 47 \mathrm{mg} \mathrm{L}^{-1}$. In the second material, 1HCPSP, after a rapid rise, the concentration of phosphate anions achieved equilibrium after $50 \mathrm{~h}$ of soaking and remained within a limit of $75 \mathrm{mg} \mathrm{L}^{-1}$.

The smallest changes occurred in the case of strontium ions. The quantity of $\mathrm{Sr}^{2+}$ released by $1 \mathrm{HCPSP}$ slightly increased as a function of time and equaled $\sim 32 \mathrm{mg} \mathrm{L}^{-1}$ after $170 \mathrm{~h}$. 
The observed ion exchange suggests the formation of a novel layer of inorganic salts containing calcium, strontium, and phosphorous ions. The concentrations of these ions depend on the initial concentrations in the scaffolds. These values clearly correspond to the mechanism described by Hench et al. [44], which suggests that there is precipitation of calcium phosphates and their derivatives at the interface of the biomaterial and the biomimetic solution. It is worth noting that silicon ions are leached from the material from the beginning of immersion in the biological medium. This phenomenon is widely considered a positive aspect of silicon-based biomaterials because silicon is treated as a substance that provides essential nourishment for the growth and maintenance of healthy bone. It is a helpful agent in building and maintaining hard tissue in different ways, including bone mineralization, reducing the number of osteoclasts that cause destruction of healthy bone, and increasing the amount of osteoblasts that regenerate bone [45]. Furthermore, in the case of $1 \mathrm{HCPP}$, the concentration of $\mathrm{PO}_{4}{ }^{3-}$ ions in DMEM increases over time. This may suggest a gradual replacement of phosphate groups with other anions, such as carbonates. In the case of 1HCPSP, this situation is reversed, which suggests that it is more likely that phosphate salts are crystallizing on the material's surface. This was confirmed using FT-IR spectroscopy. These analyses also suggest that ion exchange in the case of strontium-doped material $1 \mathrm{HCPSP}$ has an effect, since an equilibrium in the concentrations of selected ions is achieved more quickly and fluctuations at the beginning of soaking are not as spectacular as those noticed for 1HCPP.

During biomineralization, changes in $\mathrm{pH}$ were also observed (Fig. 6). In general, $\mathrm{pH}$ for $1 \mathrm{HCPP}$ is slightly higher than for 1HCPSP. This closely corresponds with the amount 
of $\mathrm{PO}_{4}{ }^{3-}$ anions released into the solution. In the case of $1 \mathrm{HCPP}$, the $\mathrm{PO}_{4}{ }^{3-}$ concentration is higher. Phosphates undergo hydrolysis and this leads to a decrease in $\mathrm{H}^{+}$concentration and increasing $\mathrm{pH}$ values. This may also confirm that, in the case of $1 \mathrm{HCPSP}$, the surface is more favorable to phosphate salts than carbonates. This phenomenon is also confirmed by X-ray powder diffraction analysis of the precipitate scraped away from the scaffolds after biomineralization, e.g. diffraction peaks assigned to a bone-like apatite are observed at about 31.9 and $46.6^{\circ}$.

\subsection{Synthetic hydroxyapatite}

Owing to its chemical similarity to the mineral component of the bone [38], hydroxyapatite is considered one of the most important materials in biomedical applications. Synthetic hydroxyapatite $\left(\mathrm{Ca}_{10}\left(\mathrm{PO}_{4}\right)_{6}(\mathrm{OH})_{2}\right)$ is a material that has been successfully used as a filler of small bone defects and coating material to improve the biocompatibility of various implants. The particular interest in hydroxyapatite is for use as a bone substitute in dental and orthopedic implants, but because of its poor mechanical properties it cannot be applied to highly loaded components. In such cases, hydroxyapatite can only be used as a coating to improve materials properties [46].

In this study, synthetic hydroxyapatite was used to cover the synthesized scaffolds. As shown in Fig. 7, synthetic hydroxyapatite ideally covers the scaffold's surface. It is worth noting that the macropores are not closed or blocked, so do not preventing mass transport inside the network. 


\subsection{Properties of the organic-inorganic hybrid system}

These studies are preliminary in nature, to collect data concerning the properties of the resulting materials. Depending on the properties to be determined, samples were examined in the form of thin films, monoliths, or scaffolds. Only pure samples were used in these studies. No samples after biomineralization or coating with synthetic hydroxyapatite were analyzed.

Compressive strength and Young's modulus were studied for both 1HCPP and 1HCPSP. Studies were performed for two different structures, monoliths and threedimensional scaffolds. To obtain monoliths, composites were collected into polypropylene molds directly after synthesis and cured at $65^{\circ} \mathrm{C}$ for $12 \mathrm{~h}$. Scaffolds were obtained as described in Experimental Section. The results are shown in Table 2 and Fig. 8.

The mechanical properties of monoliths are similar to those observed for cortical bone, whereas scaffolds seems to be perfect candidates for sophisticated cancellous bone replacements [24, 38, 47]. The values of Young's modulus and compressive strength are better than those observed for tricalcium phosphate and its composites with 2-hydroxyethylmethacrylate, 3-methacryloxypropyltrimethoxysilane, and methacrylate [48-53]. It should be noted the target mechanical properties which have been explicitly stated in the literature, span several different approaches which have been taken with regard to the design for mechanical properties. Some of them have stated that bone scaffold properties should match those of natural bone [54]. Moreover, such scaffold must be sufficient and not collapse during handling and patient's normal activity [55]. 
The results shown in Table 3 demonstrate that the presence of $\mathrm{Sr}^{2+}$-dopant in the organic-inorganic hybrid composition had some influence on the wettability of the resulting coatings. The systems with $\mathrm{Sr}^{2+}$ ions exhibited smaller contact angles than the systems without. It should be emphasized that in the case of cells and proteins, an adhesion contact angle of $\sim 65^{\circ}$ distinguishes between hydrophobic and hydrophilic surfaces [56]. Here, additional factors, such as roughness and composition of the resulting materials may have a dominant influence on cell behavior.

The synthesized hybrids can also be used as coatings on various bioinert materials, such as metallic or ceramic implants. With this use in mind, the scratch test of the resulting coatings was evaluated to determine their resistance to scratching [57-59]. We employed a calibrated set of drawing pencils ranging from $9 \mathrm{~B}$, as the softest grading, through $\mathrm{B}, \mathrm{HB}, \mathrm{F}$ and $\mathrm{H}$, to the hardest grading, $9 \mathrm{H}$. Surprisingly, the hardness of $1 \mathrm{HCP}$ and $1 \mathrm{HCPS}$ differs drastically. The surface preparation and coating process were the same in both cases. $1 \mathrm{HCP}$ seems much softer material than 1HCPS; their values in the pencil scratch hardness tests were ' $2 \mathrm{~B}$ ' and ' $8 \mathrm{H}$ ', respectively. Studies were conducted with ten independent repeats and the results were recurrent. Unfortunately, at this stage of studies it is hard to irrefutably clarify the observed values or draw any appropriate conclusions.

\subsection{Evaluation of cytotoxicity of hybrid biocomposites on human osteoblast cell line}

The survival of NHOst cells was examined using the sulforhodamine B assay. NHOst cells were incubated for $72 \mathrm{~h}$ in the presence of the test scaffolds. The control consisted of NHOst cells without test materials. 
Percentage survival was calculated using the formula:

$$
\text { Survival }[\%]=\left[\frac{A_{\mathrm{s}}-A_{\mathrm{m}}}{A_{\mathrm{c}}-A_{\mathrm{m}}} \times 100\right]
$$

where $A_{\mathrm{s}}, A_{\mathrm{m}}$, and $A_{\mathrm{c}}$ are the absorbances of the experimental samples, the control medium, and the control cells, respectively.

This study evaluated the effect of six scaffolds of $1 \mathrm{HCP}$ (after 7 days of incubation in DMEM), 1HCP_H, 1HCPP, 1HCPS (after 7 days of incubation in DMEM), 1HCPS_H, and 1HCPSP on the survival of the NHOst cell line during $72 \mathrm{~h}$ of incubation (Fig. 9 and Table 4). Our results indicate that the $1 \mathrm{HCP}$ and 1HCPS scaffolds do not show significant adverse effects on the survival of NHOst cells. Conversely, the 1HCP_H and 1HCPS_H materials significantly reduced the rate of NHOst cell survival ( $\left.{ }^{*} \mathrm{P}<0.05\right)$; the survival rates in these cases were 65 and $45 \%$, respectively. The samples of $1 \mathrm{HCPP}$ and 1HCPSP that were prepared without the biomineralization step also show an inhibitory effect on NHOst cells, with a reduction of about $20 \%$ in the survival rate compared with that of the control; however, these results are not statistically significant.

Scaffold 1HCPS were selected for the morphological studies using SEM, because NHOst cells in the presence of 1HCPS scaffold demonstrates high survival rate. In the Figure 10, SEM images illustrate the cell morphology on the resulting material.

Prior to SEM, the cells were grown on hybrid scaffolds for 20 days, following three prior inoculations of cells in the test materials. SEM after 20 days of culturing the NHOst cells on 1HCPS sample confirmed that these cells adhered to the scaffold's surface (Fig. $10)$, which is not toxic to NHOst cells. 
The sulforhodamine B assay results indicated that the $1 \mathrm{HCP}$ and $1 \mathrm{HCPS}$ scaffolds do not have a negative impact on the survival of the NHOst cell line. For this reason, they may be used in future experiments, as they do not have a toxic effect on these cells. It should be emphasized that SEM of the 1HCPS scaffold shows that not only are the cells able to survive, but they are also able to attach to and grow on this material.

\section{Conclusion}

In this work, new organic-inorganic hybrid scaffolds derived from TEVS and HEMA doped with $\mathrm{Ca}^{2+}, \mathrm{Sr}^{2+}$, and $\mathrm{PO}_{4}{ }^{3-}$ ions have been successfully developed and comprehensive characterization of the hybrid scaffolds for regenerative medicine was performed. Obtained materials possess a relatively high compressive strength, as well as high porosity (the total porous fraction for pure 1HCPP and 1HCPSP is approx. 90\%) and interconnectivity (open macropores of $150-350 \mu \mathrm{m}$ in size). The mechanical properties of monoliths are similar to those observed for cortical bone (Young's modulus: 21.3 \pm 2.4 and $21.7 \pm 2.3 \mathrm{GPa}$, and compressive strength: $201 \pm 5$ and $199 \pm 5 \mathrm{MPa}$ for 1HCPP and 1HCPSP, respectively), whereas scaffolds constitute a candidates for cancellous bone replacements (Young's modulus: $0.31 \pm 0.05$ and $0.33 \pm 0.04 \mathrm{GPa}$, and compressive strength: $2.97 \pm 0.12$ and $2.22 \pm 0.08 \mathrm{MPa}$ for $1 \mathrm{HCPP}$ and $1 \mathrm{HCPSP}$, respectively). The values of Young's modulus and compressive strength are better than those observed for tricalcium phosphate and its composites with 2hydroxyethylmethacrylate, 3-methacryloxypropyltrimethoxysilane, and methacrylate. These materials possess a sufficient shelf life ( 6 months), in the liquid form before curing, which is important for an easy and wide distribution. The incorporation of 
$\mathrm{Sr}^{2+}$ ions into the hybrid scaffolds was non-cytotoxic to the osteoblast cells. Moreover, obtained materials create a favourable rough topography which is friendly for cellular attachment and growth on the material surface. For this reason, they may be used in future in vivo experiments. Moreover, it should be noted that formulations possessing this sort of matrix with mentioned above dopants have not been studied so far, both taking into consideration their chemical and mechanical properties, and also in vitro studies.

\section{Acknowledgment}

The authors would like to express their gratitude to the National Science Centre in Poland for financial support (Grant Nos. 2013/09/D/ST8/03995 and 2012/05/N/ST8/03727).

\section{References}

[1] J. R. Jones, Review of bioactive glass: From Hench to hybrids,ActaBiomater.9 (2013) 4457-4486.

[2] E. M. Valliant, J. R. Jones, Softening bioactive glass for bone regeneration: sol-gel hybrid materials, Soft Matter 7(2011) 5083-5095.

[3] C. Seebach, J. Schultheiss, K. Wilhelm, J. Frank, D. Heinrich, Comparison of six bone-graft substitutes regarding to cell seeding efficiency, metabolism and growth behaviour of human mesenchymal stem cells (MSC) in vitro, Injury41 (2010) 731738. 
[4] S. Padilla, J. Román, A. Carenas, M. Vallet-Regi, The influence of the phosphorus content on the bioactivity of sol-gel glass ceramics, Biomaterials 26 (2005) 475-483.

[5] T. Morohashi, T. Sano, S. Yamada, Effect of strontium on calcium metabolism in rats. I. A distinction between the pharmacological and toxic doses,Jpn. J. Pharmacol. 64 (1994) 155-162.

[6] M. E. Arlot, J. P. Roux, G. Boivin, B. Perrat, Y. Tsouderos, P. Deloffre, P. J. Meunier, Effects of a strontium salt (S12911) on both tibial metaphysis and epiphysis in normal growing rats, J. Bone Miner. Res. 10 (1995) 356.

[7] P. Ammann, R. Rizzoli, P. Deloffre, Y. Tsouderos, J. M. Meyer, J. P. Bonjour, Long term administration of a high dose of the strontium salt S 12911 has no toxic effect on bone biomechanics in female rats and may improve bone strength of the midshafthumerus, J. Bone Miner. Res. 10 (1995) 358.

[8] S. P. Nielsen, The biological role of strontium, Bone 35 (2004) 583-588.

[9] X. Wang, Z. Gu, B. Jiang, L. Li, X. Yu, Surface modification of strontium-doped porous bioactive ceramic scaffolds via poly(DOPA) coating and immobilizing silk fibroin for excellent angiogenic and osteogenic properties, Biomater. Sci. 4 (2016) 678-688.

[10] S. Ray, U. Thormann, U. Sommer, T. E. Khassawna, M. Hundgeburth, A. Henß, M. Rohnke, K. S. Lips, C. Heiss, S. Heinemann, T. Hanke, L. Dürselen, R. Schnettler, V. Alt, Effects of macroporous, strontium loaded xerogel-scaffolds on new bone formation in critical-size metaphyseal fracture defects in ovariectomized rats, Injury 47 (2016) 5261. 
[11] L. Weng, M. J. Teusink, F. D. Shuler, V. Parecki, J. Xie, Highly controlled coating of strontium-doped hydroxyapatite on electrospun poly( $\varepsilon$-caprolactone) fibers, J. Biomed. Mater. Res. B Appl. Biomater. (2016), doi: 10.1002/jbm.b.33598.

[12] J. Jensen, J. H. Stang, B. Kringsholm, G. Pritzl, Relationship between trace element content and mechanical bone strength, Bone 20 (1997) 104-108.

[13] A. E. Sobel, Y. Cohen, B. Kramer, The nature of the injury to the calcifying mechanisms in rickets due to strontium, Biochem. J. 29 (1935) 2640-2645.

[14] P. J. Meunier, C. Roux, S. Ortolani, M. Diaz-Curiel, J. Compston, P. Marquis, C. Cormier, G. Isaia, J. Badurski, J. D. Wark, J. Collette, J. Y. Reginster,Effects of longterm strontium ranelate treatment on vertebral fracture risk in postmenopausal women with osteoporosis,Osteoporos. Int.20 (2009) 1663-1673.

[15] O. Bruyere, C. Roux, J. Badurski, G. Isaia, M. C. de Vernejoul, J. Cannata, S. Ortolani, D. Slosman, J. Detilleux, J. Y. Reginster, Relationship between change in femoral neck bone mineral density and hip fracture incidence during treatment with strontium ranelate,Curr. Med. Res. Opin. 23 (2007) 3041-3045.

[16] J. P. Marie, Strontium as therapy for osteoporosis,Curr. Opin. Pharm. 5 (2005) 633-636.

[17] M. D. Grynpas, E. Hamilton, R. Cheung, Y. Tsouderos, P. Deloffre, M. Hott, P. J. Marie, Strontium increases vertebral bone volume in rats at a low dose that does not induce detectable mineralization defect, Bone 18 (1996) 253-259.

[18] R. Baron, Y. Tsouderos, In vitro effects of S12911-2 on osteoclast function and bone marrow macrophage differentiation, Eur. J. Pharmacol. 450 (2002) 11-17. 
[19] N. Takahashi, T. Sasaki, Y. Tsouderos, T. Suda, S12911-2 inhibits osteoclastic bone resorption in vitro, J. Bone Miner. Res. 18 (2003) 1082-1087.

[20] W. Xue, J. J. Moore, H. L. Hosick, S. Bose, A. Bandyopadhyay, W. W. Lu, K. M. C. Cheung, K. D. K. Luk,Osteoprecursor cell response to strontium-containing hydroxyapatite ceramics, J. Biomed. Res. A 79A (2006) 804-814.

[21] J. P. Montheard, J. Kahovec, D. Chappard,Homopolymers and copolymers of 2hydroxyethyl Methacrylate for biomedical applications. In Desk reference of functional polymers; Syntheses and applications,R. Arshady, Ed., American Chemical Society, Washington DC, Chapter 5.3(1997) 699-717.

[22] P. Sharrock, G. Gregoire, HEMA reactivity with demineralized dentin, J. Dent. 38 (2010) 331-335.

[23] T. Keaveny, W. Hayes, Mechanical properties of cortical and trabecular bone. In: Bone growth, Boca Raton, FL: CRC Press (1993) 285-344.

[24] P. Zioupos, J. D. Currey, Changes in the stiffness, strength, and toughness of human cortical bone with age, Bone 22 (1998) 57-66.

[25] E. Sedlin, A rheologic model for cortical bone - a study of physical properties of human femoral samples,ActaOrthop. Scand.S83 (1965) 1-77.

[26] X. N. Dong, X. E. Guo, The dependence of transversely isotropic elasticity of human femoral cortical bone on porosity, J.Biomech.37 (2004) 1281-1287.

[27] E. Giesen, M. Ding, M. Dalstra, T. van Eijden, Mechanical properties of cancellous bone in the human mandibular condyle are anisotropic, J.Biomech.34 (2001) 799-803.

[28] L. Rohl, E. Larsen, F. Linde, A. Odgaard, J. Jorgensen, Tensile and compressive properties of cancellous bone, J.Biomech.24 (1991) 1143-1149. 
[29] Y. Yeni, D. Fyhrie, Finite element calculated uniaxial apparent stiffness is a consistent predictor of uniaxial apparent strength in human vertebral cancellous bone tested with different boundary conditions, J.Biomech.34 (2001) 1649-1654.

[30] D. Carter, W...Hayes, The compressive behavior of bone as a two-phase porous structure, J. Bone Joint Surg.59A (1977) 954-962.

[31] A. Rudawska, E. Jacniacka, Analysis of determining surface free energy uncertainty with the Owens-Wendt method, Int. J. Adhes. Adhes. 29 (2009) 451-457.

[32] D. Kubies, L. Himmlova, T. Riedel, E. Chanova, K. Balik, M. Douderova, J. Bartova, V. Pesakova, The interaction of osteoblasts with bone-implant materials: 1 . The effect of physicochemical surface properties of implant materials, Physiol. Res. 60 (2011) 95-111.

[33] Ł. John, M. Bałtrukiewicz, P. Sobota, R. Brykner, Ł. Cwynar-Zając, P. Dzięgiel Non-cytotoxic organic-inorganic hybrid bioscaffolds: An efficient bedding for rapid growth of bone-like apatite and cell proliferation, Mater. Sci. Eng. C 32 (2012) 18491858.

[34] P. Skehan, R. Storeng, D. Scudiero, A. Monks, J. McMahon, D. Vistica, J. T. Warren, H. Bokesch, S. Kenney, R. M. Boyd, New colorimetric cytotoxicity assay for anticancer-drug screening, J. Nat. Cancer Inst. 82 (1990) 1107-1112.

[35] M. Vallet-Regi, Ordered mespoporous materials in the context of drug delivery systems and bone tissue engineering, Chem. Eur. J.12 (2006) 5934-5943.

[36] L. Verestiuc, O. Nastasescu, E. Barbu, I. Sarvaiya, K. L. Green, J. Tsibouklis, Functionalized chitosan/NIPAM (HEMA) hybrid polymer networks as inserts for ocular drug delivery: synthesis, in vitro assessment, and in vivo evaluation, J. Biomed. Mater. Res. A 77 (2006) 726-35. 
[37] O. Tsigkou, J. R. Jones, J. M. Polak, M. M. Stevens, Differentiation of fetal osteoblasts and formation of mineralized bone nodules by $45 \mathrm{~S} 5$ Bioglass $\AA$ conditioned medium in the absence of osteogenic supplements, Biomaterials 30 (2009) 3542-3550.

[38] J.-Y. Rho, L. Kuhn-Spearing, P. Zioupos, Mechanical properties and the hierarchical structure of bone, Med. Eng. Phys. 20 (1998) 92-102.

[39] V. Karageorgiou, D. Kaplan, Porosity of 3D biomaterial scaffolds and osteogenesis, Biomaterials 26 (2005) 5474-5491.

[40] K. Hatano, H. Inoue, T. Kojo, T. Tsujisawa, C. Uchiyama, Y. Uchida, Effect of surface roughness on proliferation and alkaline phosphatase expression of rat calvarial cells cultured on polystyrene, Bone 25 (1999) 439-445.

[41] G. Wang, L. Zheng, H. Zhao, J. Miao, C. Sun, H. Liu, Z. Huang, X. Yu, J. Wang, X. Tao, Construction of a fluorescent nanostructured chitosan-hydroxyapatite scaffold by nanocrystalion induced biomimetic mineralization and its cell biocompatibility, ACS Appl. Mater. Interfaces 3 (2011) 1692-1701.

[42] J. Soulie, A. Hardy-Desources, J.-M. Nedelec, E. Jallot, 3D organized macroporous bioactive glasses: A study of pore size effect on physicochemical reactivity by micro-PIXE-RBS, J. Phys. Chem. C 117 (2013) 6702-6711.

[43] E. Jallot, J. Lao, Ł. John, J. Soulié, Ph. Moretto, J.-M. Nedelec, Imaging physicochemical reactions occuring at the pore surface in binary bioactive glass foams by micro ion beam analysis, ACS Appl. Mater. Interfaces 2 (2010) 1737-1742.

[44] L. L. Hench, I. Thompson, Twenty-first century challenges for biomaterials, J. R. Soc. Interface 7 (2010) S379-S391. 
[45] C. D. Seaborn, F. H. Nielsen, Silicon deprivation decreases collagen formation in wounds and bone, and ornithine transaminase activity in liver, Biol. Trace Elem. Res. 89 (2002) 251-261.

[46] K. Lin, J. Chang, Structure and properties of hydroxyapatite for biomedical applications. In Hydroxyapatite (Hap) for Biomedical Applications, Ed. by M. R.Mucalo, A volume in Woodhead Publishing Series in Biomaterials (2015) 3-19.

[47] F. Mammeri, E. Le Bourhis, L. Rozes, C. Sanchez, Mechanical properties of hybrid organic-inorganic materials, J. Mater. Chem. 15 (2005) 3787-3811.

[48] A. J. Wagoner Johnson, B. A. Herschler, A review of the mechanical behavior of $\mathrm{CaP}$ and $\mathrm{CaP} /$ polymer composites for applications in bone replacement and repair, ActaBiomater. 7 (2011) 16-30 and references therein.

[49] T. Uchino, M. Kamitakahara, M. Otsuka, C. Ohtsuki, Hydroxyapatite-forming capability and mechanical properties of organic-inorganic hybrids and $\alpha$-tricalcium phosphate porous bodies, J. Ceram. Soc. Japan 118 (2010) 57-61.

[50] H. Zreiqat, Y. Ramaswamy, Ch. Wu, A. Paschalidis, ZuFu Lu, B.James, O. Birke, M. McDonald, D. Little, C. R. Dunstan, The incorporation of strontium and zinc into a calcium-silicon ceramic for bone tissue engineering, Biomaterials 31 (2010) 31753184.

[51] C. Wu, Y. Ramaswamy, P. Boughton, H. Zreiqat, Improvement of mechanical and biological properties of porous $\mathrm{CaSiO}_{3}$ scaffolds by poly(D,L-lactic acid) modification,ActaBiomater.4 (2008) 343-53.

[52] H. W. Kim, J. C. Knowles, H. E. Kim, Hydroxyapatite porous scaffold engineered with biological polymer hybrid coating for antibiotic vancomycin release, J. Mater. Sci. Mater. Med.16 (2005) 189-95. 
[53] Q. Z. Chen, I. D. Thompson, A. R. Boccaccini, 45S5 Bioglass-derived glassceramic scaffolds for bone tissue engineering, Biomaterials 27 (2006) 2414-25.

[54] M. D. Kwan, D. C. Wan, M. T. Longaker, Skeletal-tissue engineering, In: Principles of tissue engineering, Burlington, Academic Press (2007) 935-44.

[55] K. Rezwan, Q. Chen, J. Blaker, A. Boccaccini, Biodegradable and bioactive porous polymer/inorganic composite scaffolds for bone tissue engineering, Biomaterials 27 (2006) 3413-31.

[56] J. Y. Lim, M. C. Shaughnessy, Z. Y. Zhou, H. Noh, E. A. Vogler, H. J. Donahue, Surface energy effects on osteoblast spatial growth and mineralization, Biomaterials 29 (2008) 1776-1784.

[57] S. Peng, Z. Zeng, W. Zhao, J. Chen, J. Han, X. Wu, Performance evaluation of mercapto functional hybrid silica sol-gel coating on copper surface, Surf. Coat. Technol. 251 (2014) 135-142.

[58] L. Sowntharya, G. Ravi Chandra, K. R. C. Soma Raju, R. Subasri, Effect of addition of surface modified nanosilica into silica-zirconia hybrid sol-gel matrix, Ceram. Int. 39 (2013) 4245-4252.

[59] Y. Wang, H. Wang, X. Meng, R. Chen, Antireflective films with Si-O-P linkages from aqueous colloidal silica: Preparation, formation mechanism and property, Sol. Energ. Mat. Sol. C130 (2014) 71-82. 
Figures and Tables

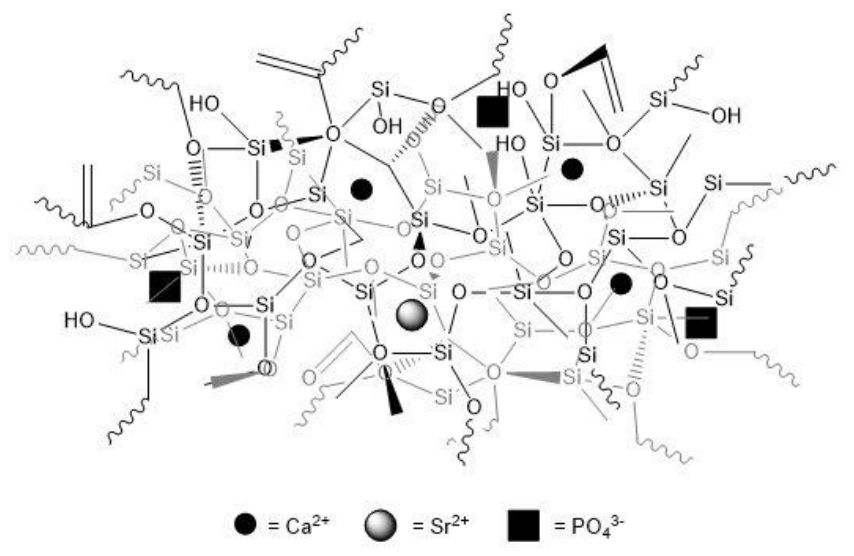

Figure 1. Ramified structure of the organic-inorganic hybrid network.
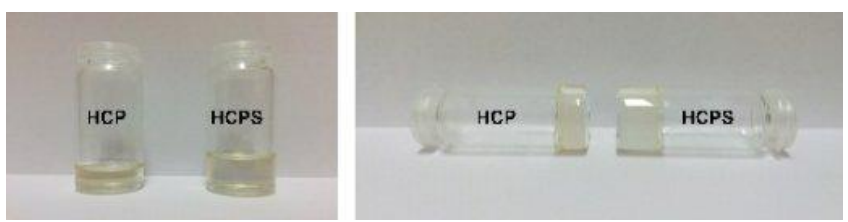

Figure 2. Homogeneous and transparent gels of resulting materials.
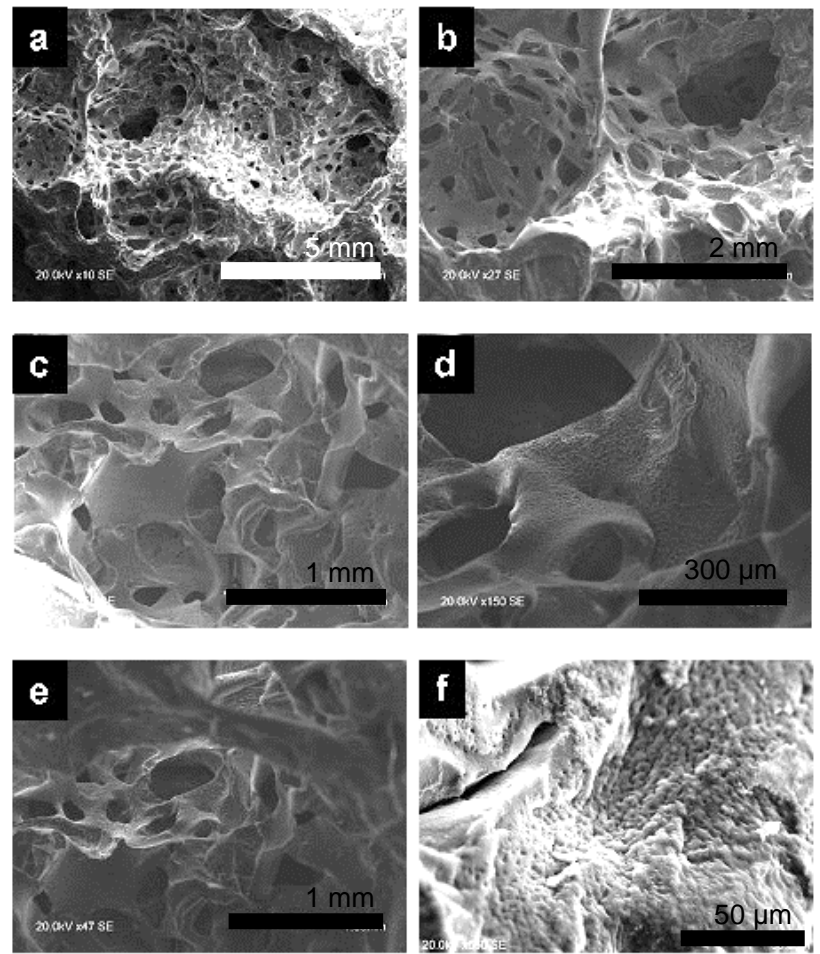

Figure 3. Resulting hybrid networks: (a-c) 1HCPP, (d-f) 1HCPSP. 


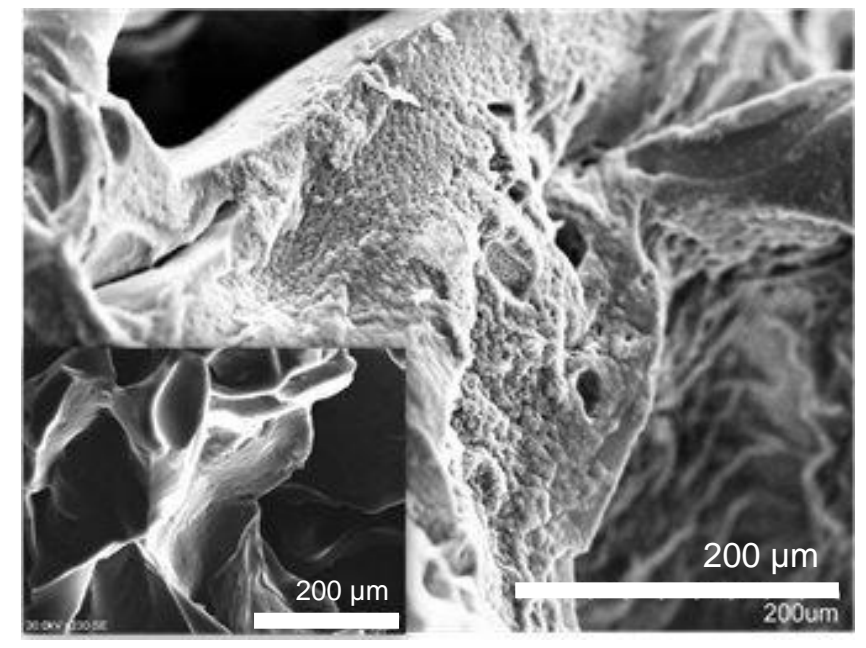

Figure 4. Addition of ammonia carbonate to sugar porogen forms rough scaffold surface. Inset: surface without the addition $\left(\mathrm{NH}_{4}\right)_{2} \mathrm{CO}_{3}$.
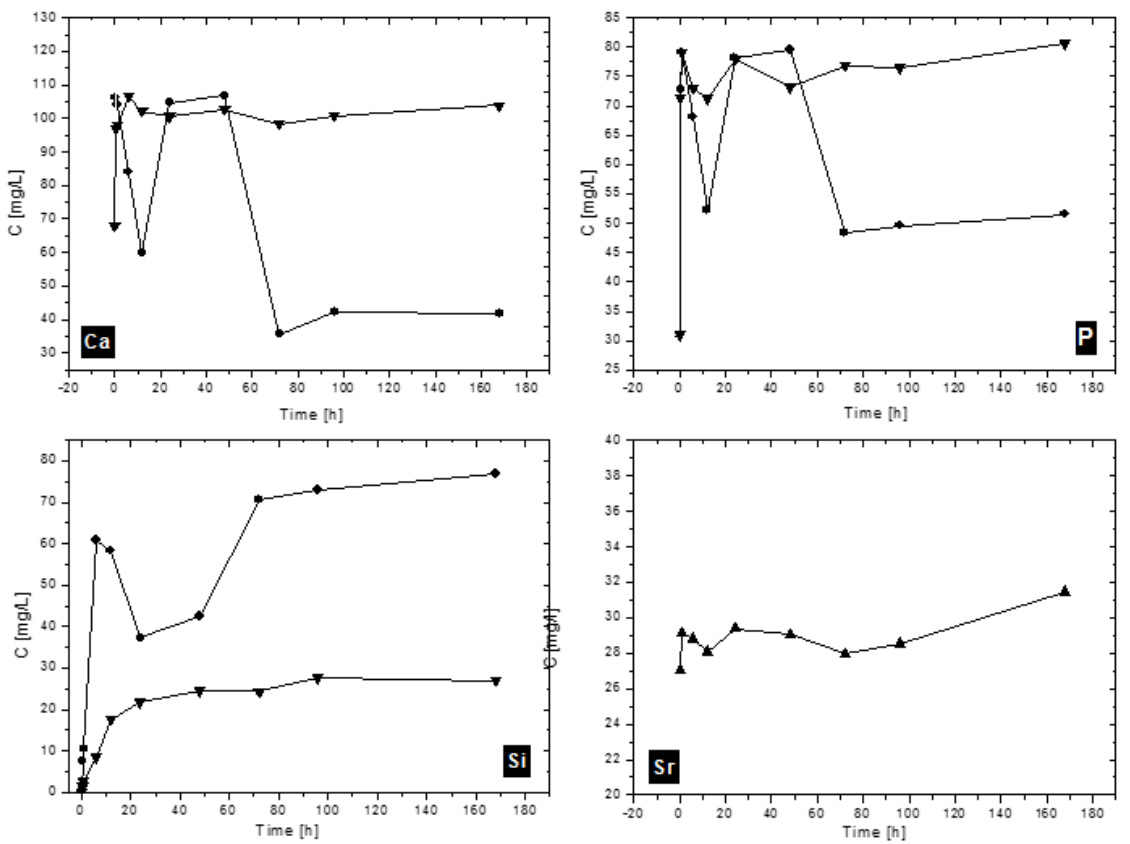

Figure 5. Inductively coupled plasma analysis of the evolution of $\mathrm{Ca}^{2+}, \mathrm{Si}^{4+}, \mathrm{PO}_{4}{ }^{3-}$ and $\mathrm{Sr}^{2+}$ ions $\left(\mathrm{mg} \mathrm{L}^{-1}\right)$ in DMEM. Dots, 1HCPP; triangles, 1HCPSP. 


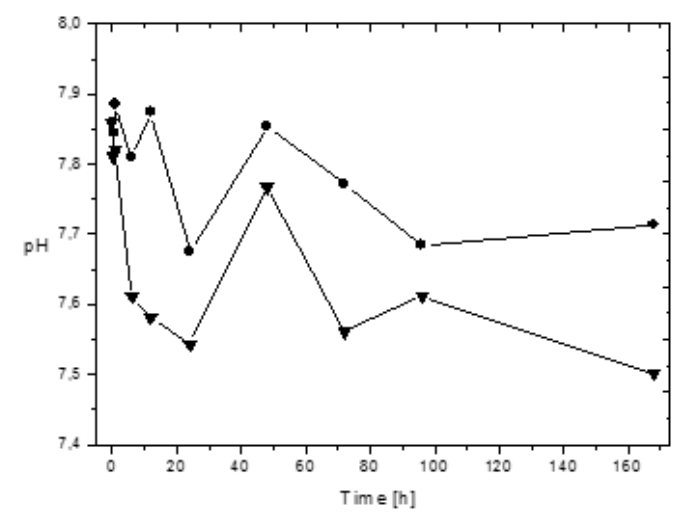

Figure 6. Changes in $\mathrm{pH}$ in DMEM during biomineralization. Dots, 1HCPP; triangles, 1 HCPSP.

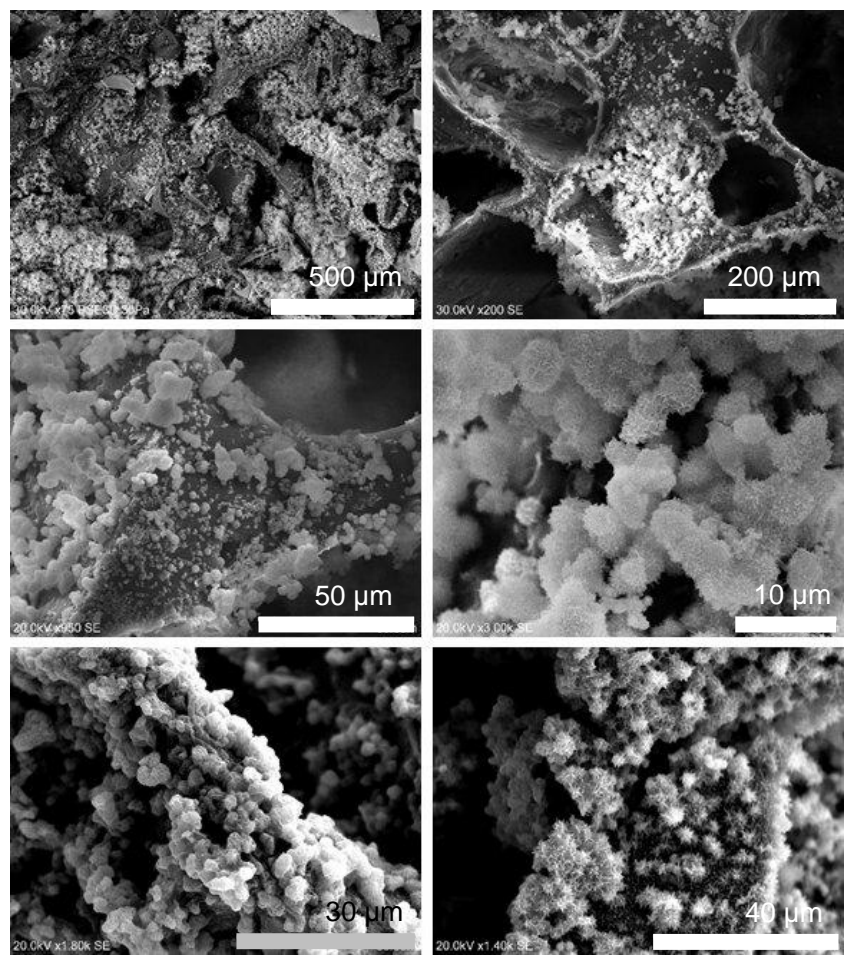

Figure 7. Scaffolds "decorated" by synthetic hydroxyapatite. 


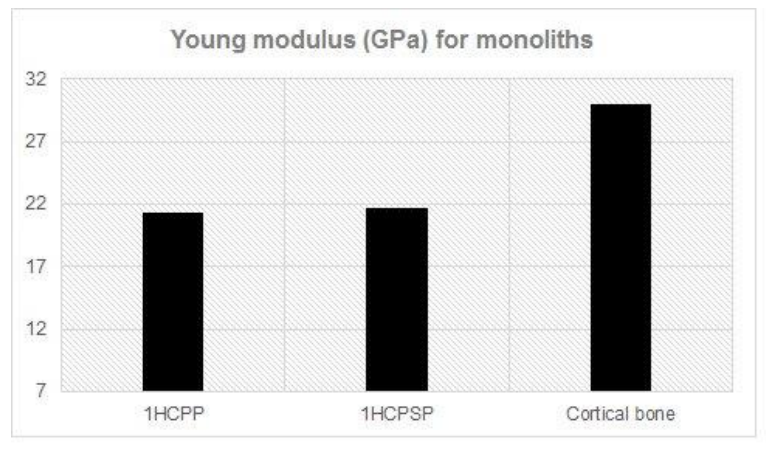

Young modulus (GPa) for scaffolds

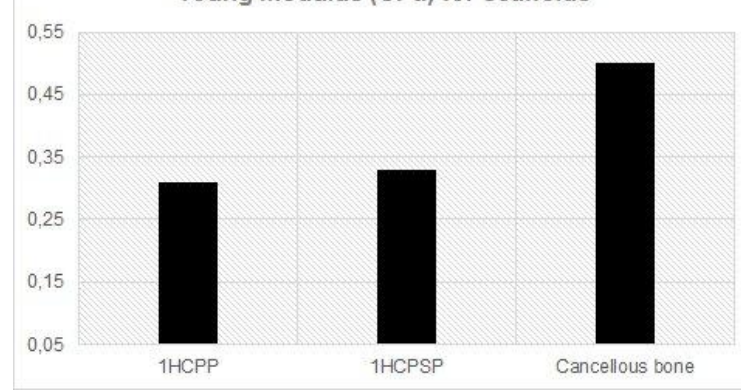

Compressive strength (MPa) for monoliths

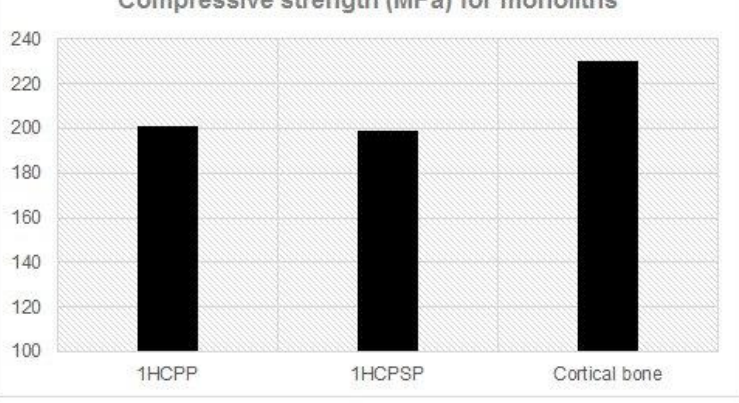

Compressive strength (MPa) for scaffolds

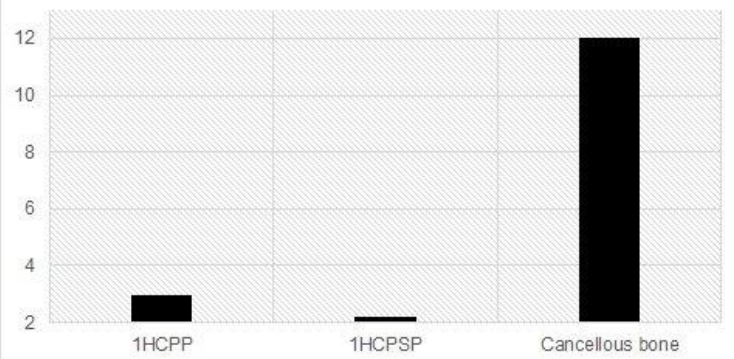

Figure 8. Mechanical properties of organic-inorganic hybrids, compared with cortical and cancellous bone.
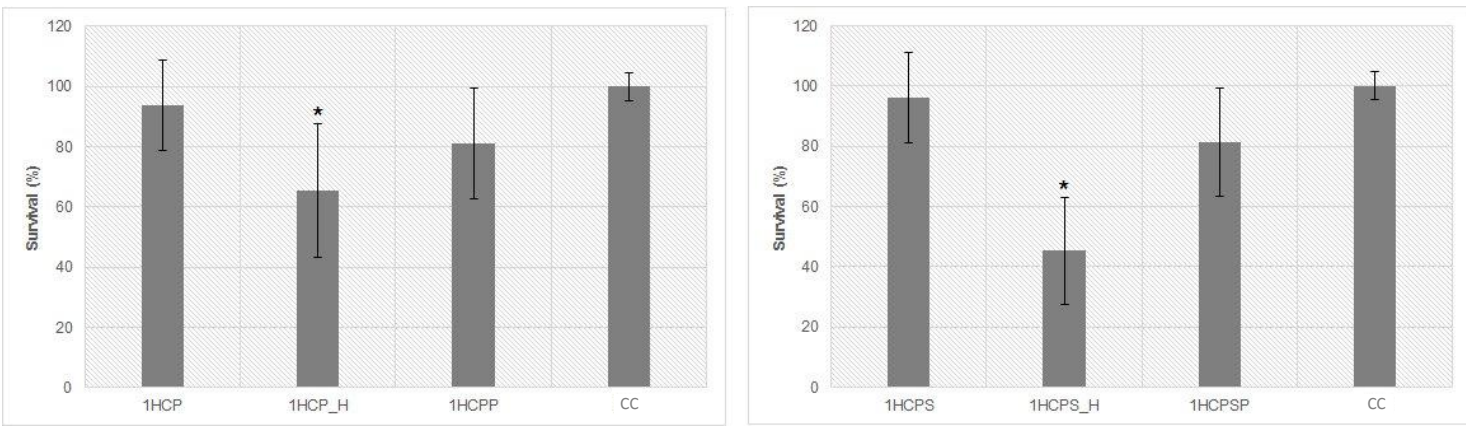

Figure 9.NHOst cell survival in the presence of organic-inorganic hybrid scaffolds after $72 \mathrm{~h}$ of incubation. The control consisted of NHOst cells without test scaffolds. ${ }^{*} \mathrm{P}<0.05$ vs. control cells (CC). Results for (left) 1HCP, 1HCP_H, and 1HCPP; (right) 1HCPS, 1HCPS_H, and 1HCPSP.
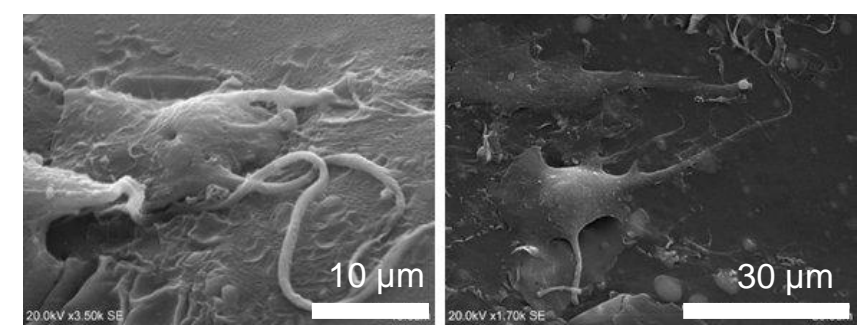

Figure 10.NHOst cells on a scaffold of $1 \mathrm{HCPS}$ after 20 days of culture. NHOst cells can be seen attached to the surface with numerous projections. 
Table 1. Compositions of the organic-inorganic hybrid materials.

\begin{tabular}{|c|c|c|c|c|c|}
\hline Samples & $\begin{array}{c}\text { TEVS : HEMA } \\
\text { ratio }\end{array}$ & $\mathrm{Ca}^{2+}(\%)$ & $\mathrm{PO}_{4}^{3-}(\%)$ & $\mathrm{Sr}^{2+}(\%)$ & Comments \\
\hline $1 \mathrm{HCP}$ & \multirow{6}{*}{$1: 4$} & \multirow{3}{*}{15.0} & \multirow{3}{*}{12.5} & \multirow{3}{*}{0.00} & $\begin{array}{l}\text { biomineralized in the biological } \\
\text { fluid }\end{array}$ \\
\hline 1HCP_H & & & & & covered by the synthetic HAp \\
\hline 1HCPP & & & & & pure, without biomineralization \\
\hline $1 \mathrm{HCPS}$ & & \multirow{3}{*}{15.0} & \multirow{3}{*}{12.5} & \multirow{3}{*}{10.0} & $\begin{array}{l}\text { biomineralized in the biological } \\
\text { fluid }\end{array}$ \\
\hline 1HCPS_H & & & & & covered by the synthetic HAp \\
\hline 1HCPSP & & & & & pure, without biomineralization \\
\hline
\end{tabular}

Table 2. Mechanical properties of organic-inorganic hybrids and some examples of selected systems.

\begin{tabular}{ccc}
\hline Materials & Young's modulus $(\mathrm{GPa})$ & Compressive strength $(\mathrm{MPa})$ \\
\hline 1HCPP & $21.3 \pm 2.4^{*} / 0.31 \pm 0.05^{* *}$ & $201 \pm 5^{\star} / 2.97 \pm 0.12^{\star *}$ \\
1HCPSP & $21.7 \pm 2.3^{*} / 0.33 \pm 0.04^{* *}$ & $199 \pm 5^{\star} / 2.22 \pm 0.08^{* \star}$ \\
\hline TCP [48,49] & $0.025 \pm 0.003$ & $0.59 \pm 0.16$ \\
TCP/HEMA/MPS [48,49] & $1.21 \pm 0.33$ & $57.4 \pm 27.5$ \\
TCP/MMA/MPS [48,49] & $2.48 \pm 0.15$ & $94.2 \pm 6.6$ \\
MMA/MPS [48-50] & $2.03 \pm 0.09$ & $110 \pm 2$ \\
\hline Cortical bone [48-53] & $7.00-30.0$ & $100-230$ \\
Cancellous bone [48-53] & $0.5-0.05$ & $2-12$
\end{tabular}

HEMA, 2-hydroxyethylmethacrylate; MMA, methacrylate; MPS, 3methacryloxypropyltrimethoxysilane; TCP, tricalcium phosphate porous body; ${ }^{*}$ monoliths; ${ }^{* *}$ scaffolds.

Table 3. Contact angle and surface free energy (Owens-Wendt method) for organicinorganic hybrids.

\begin{tabular}{lccccc}
\hline \multirow{2}{*}{ materials } & \multicolumn{2}{c}{ contact angle $\left(^{\circ}\right)$} & \multirow{2}{*}{$\mathrm{Y}^{d}$} & $\mathrm{Y}^{p}$ & SFE \\
\cline { 2 - 3 } & $\mathrm{H}_{2} \mathrm{O}$ & $\mathrm{CH}_{2} \mathrm{I}_{2}$ & & & \\
\hline 1THCP & 69.5400 & 35.7700 & 0.1273 & 90.3916 & 90.5189 \\
1THCPS & 63.2100 & 34.8600 & 5.2626 & 69.4572 & 74.7198 \\
\hline
\end{tabular}


Table 4.NHOst cell survival in the presence of $1 \mathrm{HCP}, 1 \mathrm{HCP} \mathrm{H}, 1 \mathrm{HCPP}, 1 \mathrm{HCPS}$, 1HCPS_H, and 1HCPSP scaffolds after $72 \mathrm{~h}$ of incubation.

\begin{tabular}{cccccccc}
\hline & 1HCP & 1HCP_H & 1HCPP & 1HCPS & 1HCPS_H & 1HCPSP & CC \\
\hline $\begin{array}{c}\text { Mean } \\
(\%)\end{array}$ & 93.68 & 65.52 & 81.12 & 96.10 & 45.29 & 81.43 & 100.00 \\
SD (\%) & 14.90 & 22.25 & 18.51 & 15.03 & 17.72 & 17.97 & 4.62 \\
\hline
\end{tabular}

